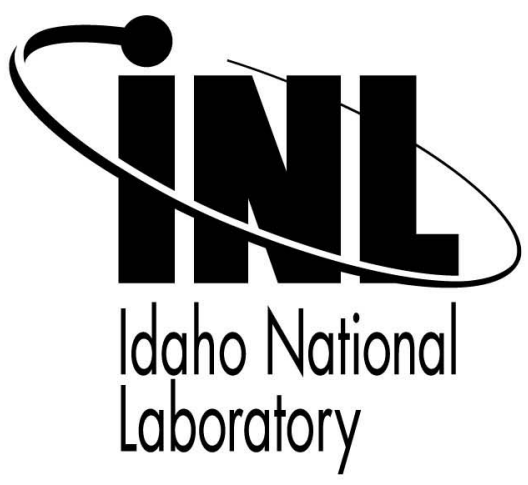

\title{
Estimation of Critical Flow Velocity for Collapse of Gas Test Loop Booster Fuel Assembly
}

\author{
ICONE 14
}

Donna Post Guillen

Mark J. Russell

July 2006

This is a preprint of a paper intended for publication in a journal or proceedings. Since changes may be made before publication, this preprint should not be cited or reproduced without permission of the author. This document was prepared as an account of work sponsored by an agency of the United States Government. Neither the United States Government nor any agency thereof, or any of their employees, makes any warranty, expressed or implied, or assumes any legal liability or responsibility for any third party's use, or the results of such use, of any information, apparatus, product or process disclosed in this report, or represents that its use by such third party would not infringe privately owned rights. The views expressed in this paper are not necessarily those of the United States Government or the sponsoring agency. 


\title{
ICONE14-89130
}

\section{ESTIMATION OF CRITICAL FLOW VELOCITY FOR COLLAPSE OF GAS TEST LOOP BOOSTER FUEL ASSEMBLY}

\author{
Donna Post Guillen and Mark J. Russell \\ Idaho National Laboratory \\ Idaho Falls, Idaho 83415
}

\begin{abstract}
This paper presents calculations performed to determine the critical flow velocity for plate collapse due to static instability for the Gas Test Loop booster fuel assembly. Long, slender plates arranged in a parallel configuration can experience static divergence and collapse at sufficiently high coolant flow rates. Such collapse was exhibited by the Oak Ridge High Flux Reactor in the 1940s and the Engineering Test Reactor at the Idaho National Laboratory in the 1950s. Theoretical formulas outlined by Miller, based upon widebeam theory and Bernoulli's equation, were used for the analysis. Calculations based upon Miller's theory show that the actual coolant flow velocity is only $6 \%$ of the predicted critical flow velocity. Since there is a considerable margin between the theoretically predicted plate collapse velocity and the design velocity, the phenomena of plate collapse due to static instability is unlikely.
\end{abstract}

\section{INTRODUCTION}

A Gas Test Loop (GTL) system is currently being designed to provide a high intensity fast-flux irradiation environment for testing fuels and materials for advanced concept nuclear reactors. To assess the performance of candidate reactor fuels, these fuels must be irradiated under actual fast reactor flux conditions and operating environments, preferably in an existing irradiation facility [1]. The GTL system is being designed for operation in the northwest test lobe of the Advanced Test Reactor (ATR) at the Idaho National Laboratory. The Technical and Functional Requirements (T\&FRs) for the GTL stipulate a minimum neutron flux intensity $\left(10^{15} \mathrm{n} / \mathrm{cm}^{2} \cdot \mathrm{s}\right)$ and fast to thermal neutron ratio $(>15)$ for the test environment [2]. Incorporation of booster fuel within the test lobe is necessary to achieve these neutron flux requirements.

The current design of the booster fuel assembly (BFA) for the GTL calls for 3 concentric rings of uranium silicide fuel plates clad with 6061 aluminum arranged in four quadrants (shown in Figure 1). The fuel plates are 0.1 inches $(0.254 \mathrm{~cm})$ thick, 4 foot $(1.22 \mathrm{~m})$ long, and separated by 0.078 inch $(0.198 \mathrm{~cm})$ water coolant channels.

\section{PLATE COLLAPSE PHENOMENON}

Long parallel plate fuel assemblies can experience static divergence and collapse at sufficiently high coolant flow rates. Such phenomenon has occurred at the Oak Ridge High Flux Reactor [3] in the 1940s and the Engineering Test Reactor at the Idaho National Laboratory [4] in the 1950s. When the coolant flow reaches a critical static divergent velocity, $\mathrm{U}_{\mathrm{d}}$, parallel plate fuel assemblies will buckle and collapse onto each other as a result of a flow-induced asymmetric pressure distribution in adjacent flow channels [5]. Analysis was performed herein to determine whether the GTL booster fuel assembly (BFA) is likely to collapse at the current design flow rate due to a flow-induced staticinstability type of failure.

Fuel plate collapse stems from plate deformation, which can be caused by unbalanced channel pressures created by turbulence, pressure fluctuations produced by the primary coolant pumps, unequal flow in the channels due to assembly tolerances, etc. Pressure forces act to deflect the fuel plates. Excessive lateral deformation of long parallel plates subject to axial flow can occur due to unbalanced channel pressures when the pressure difference across the plates is too large for the plate to resist [6]. As the plates deform and the flow 
channel narrows, the flow velocity increases. By Bernoulli's equation, the pressure correspondingly decreases, and this causes an increase of the pressure differential across the plate with a corresponding increase in deformation. This deformation is resisted by elastic restoring forces developed in 


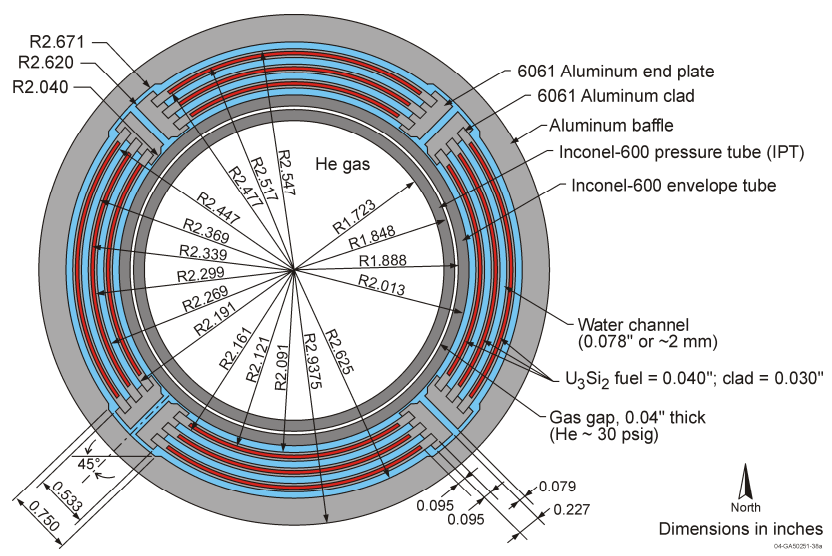

Fig. 1. Current booster fuel assembly configuration and dimensions.

the plate as a result of the deformation. As the flow velocity reaches the critical velocity, the relationship between pressure, flow and deflection becomes one of positive feedback, so that the pressure increase and lateral deflection increase without any further external increase of fluid flow. This effect can lead to large plate deflections and overheating of the fuel plates given critical fluid velocities.

\section{SOLUTION METHODOLOGY}

The theoretical formulas outlined by Miller [3], based upon wide-beam theory and Bernoulli's equation, were used for the analysis. Although Miller's theoretical collapse velocity is a simplified model of a complicated system, it remains widely used due to its ease of use in predicting an approximate collapse velocity [6]. The method is applicable to plates with a length much larger than their width, with the long edges restrained by attachment to side plates, and assembled with uniform spacing. Plate assemblies with low aspect ratios, such as those considered here, are prone to lose stability by divergence whereas short, wide plate configurations are prone to flutter [7].

Assumptions made in the analysis include:

- $\quad$ Fuel plates are uniformly curved with the longitudinal edges hinged (pinned) to rigid side plates. Assuming pinned edge boundary conditions, rather than fixed edges, is conservative (i.e., yields a lower critical velocity) since a more flexible structure exhibits larger deflections in response to a given pressure differential. It is worth pointing out that the actual fuel plates will be attached to the side plates by crimping with a special jig, whereas the mockup fuel plates for the hydraulic flow test will be glued in place. If the hydraulic flow test model is to be used for vibration and/or plate collapse testing, this could affect the results since the boundary conditions are different.

- Coolant flow is incompressible and all channels have the same mass flow, which is uniform across any plate channel section.

- There is no flow across the channels. This is a conservative assumption since "windows" in the fuel side plates will allow flow between adjacent channels if there is a pressure difference to drive the lateral flow.
- $\quad$ There are no stabilization combs. In practice there will be stabilization combs at the leading and trailing edges (i.e., top and bottom) of the plates that will help steady the fuel plates from flow-induced vibration mechanisms, such as turbulence, vortex shedding and fluid-elastic instability. The presence of the combs will serve to increase the critical velocity.

- Material properties for aluminum are applicable for the plates since the outer surface (fuel cladding) is aluminum and this will dictate the buckling properties.

- This analysis does not include thermal elastic effects, growth of the fuel meat during irradiation, and transverse compressive loadings, which may also impose a negative stiffness on the fuel plates.

\section{ANALYSIS}

This calculation is based upon the method of Miller [3] for calculating the critical flow velocity of collapse to a pinned edge curved plate fuel assembly similar to the aluminum clad uranium silicide fuel for the GTL BFA.

The outer and inner radii of the silicide fuel element plates are

$$
\begin{aligned}
& \mathrm{R}_{\mathrm{o}}:=\left(\begin{array}{l}
2.547 \\
2.369 \\
2.191
\end{array}\right) \cdot \text { in } \\
& \mathrm{R}_{\mathrm{i}}:=\left(\begin{array}{l}
2.447 \\
2.269 \\
2.091
\end{array}\right) \cdot \text { in }
\end{aligned}
$$

The individual plate thicknesses are

$$
\mathrm{R}_{\mathrm{o}}-\mathrm{R}_{\mathrm{i}}=\left(\begin{array}{l}
0.1 \\
0.1 \\
0.1
\end{array}\right) \text { in }
$$

Assigning the variable, a, for plate thickness

$$
\mathrm{a}:=0.1 \cdot \text { in }
$$

Fuel plate section parameters are defined on a "per unit width basis" with an arbitrary unit width

$$
w:=1 \cdot \text { in }
$$

The area of beam cross section per unit width of beam is

$$
\mathrm{A}:=\frac{\mathrm{a} \cdot \mathrm{w}}{\mathrm{w}}
$$

and

$$
\mathrm{A}=0.1 \mathrm{in}
$$


The moment of inertia of the beam cross section per unit width of beam is given by

$$
I:=\frac{\frac{w \cdot a^{3}}{12}}{w}
$$

and

$$
\mathrm{I}=8.333 \times 10^{-5} \mathrm{in}^{3}
$$

The minimum radius of curvature of fuel plate is used to minimize the critical velocity ratio

$$
\mathrm{R}:=\min \left(\frac{\mathrm{R}_{\mathrm{O}}+\mathrm{R}_{\mathrm{i}}}{2}\right)
$$

and

$$
\mathrm{R}=2.141 \mathrm{in}
$$

Half the curved plate arc between supports, $\alpha$, is

$$
\alpha:=\frac{\pi}{4}
$$

From Miller [3]

$$
\begin{aligned}
C(\alpha):= & \frac{-2}{3}+\sin (2 \cdot \alpha) \cdot\left(\frac{3}{4} \cdot \cot (\alpha)-\alpha\right)-\frac{4}{3} \cdot \cos (2 \cdot \alpha) \ldots \\
& +\alpha \cdot \cot (\alpha) \cdot\left(1-\frac{\cos (2 \cdot \alpha)}{2}\right)
\end{aligned}
$$

and

$$
C(\alpha)=0.083
$$

Miller [3] also defines the following variables

$$
\begin{gathered}
f_{1}(\alpha):=\frac{1}{2 \cdot \sin (\alpha)^{2}} \cdot\left(\frac{\alpha}{2}+\frac{\sin (2 \cdot \alpha)}{4}\right) \\
f_{3}(\alpha):=\frac{1}{2 \cdot \sin (\alpha)^{2}} \cdot\left(\alpha-\frac{3}{4} \cdot \sin (2 \cdot \alpha)+\frac{\alpha \cdot \cos (2 \cdot \alpha)}{2}\right) \\
\beta_{2}:=\frac{A \cdot R^{2}}{I} \cdot f_{3}(\alpha)+f_{1}(\alpha)
\end{gathered}
$$

The ratio of pinned edge curved plate to pinned edge flat plate critical velocity is

$$
\mathrm{V}_{\mathrm{fh}}:=\left(\frac{8 \cdot \beta_{2} \cdot \sin (\alpha)^{5}}{15 \cdot C(\alpha)}\right)^{\frac{1}{2}}
$$

and

$$
\mathrm{V}_{\mathrm{th}}=14.9
$$

Now, the pinned edge velocity to which the above ratio applies is calculated. The gravitational acceleration constant is

$$
\mathrm{g}=386.089 \frac{\text { in }}{\mathrm{sec}^{2}}
$$

Young's Modulus for the fuel plate using room temperature data for aluminum (1000 series) is [8]

$$
\mathrm{E}:=10 \cdot 10^{6} \cdot \mathrm{psi}
$$

Poisson's ratio of the fuel plate is taken to be that of aluminum [9]

$$
u:=0.33
$$

The fuel element channel widths, $h_{\mathrm{el}}$, are

$$
\mathrm{h}_{\mathrm{el}_{\mathrm{i}}}:=\mathrm{R}_{\mathrm{i}_{\mathrm{i}}}-\mathrm{R}_{\mathrm{O}_{\mathrm{i}+1}}
$$

which results in an initial flow channel thickness, h, of

$$
\mathrm{h}:=\min \left(\mathrm{h}_{\mathrm{el}}\right)
$$

and

$$
\mathrm{h}=0.078 \mathrm{in}
$$

The average density of the water coolant is

$$
\rho:=62.24 \cdot \frac{\mathrm{lbf}}{\mathrm{ft}^{3}}
$$

The dimension of end plate is

$$
\text { ep }:=0.533 \cdot \mathrm{in}
$$

The width of the flat plate is taken as arc length of curved plate minus end plate

$$
\mathrm{b}:=2 \cdot \alpha \cdot \mathrm{R}-\mathrm{ep}
$$

and

$$
\mathrm{b}=2.83 \text { in }
$$


The critical velocity of pinned edge flat plate is

$$
\mathrm{V}_{s}:=\left[\frac{5 \cdot g \cdot E \cdot a^{3} \cdot h}{2 \cdot \rho \cdot b^{4} \cdot\left(1-u^{2}\right)}\right]^{\frac{1}{2}}
$$

which yields

$$
\mathrm{V}_{\mathrm{s}}=50.39 \frac{\mathrm{ft}}{\mathrm{sec}}
$$

The critical static divergent velocity for the curved plate GTL booster fuel assembly is the product

$$
\mathrm{U}_{\mathrm{d}}:=\mathrm{V}_{\mathrm{s}} \cdot \mathrm{V}_{\mathrm{fh}}
$$

which yields

$$
\mathrm{U}_{\mathrm{d}}=749.2 \frac{\mathrm{ft}}{\mathrm{sec}}
$$

The total cross-sectional flow area of the four fuel channels is

$$
\mathrm{XA}:=2.50379 \cdot 10^{-3} \cdot \mathrm{m}^{2}
$$

The total coolant flow rate necessary to produce plate collapse is the product of the cross-sectional flow area and the critical static divergent velocity

$$
\mathrm{Q}:=\mathrm{U}_{\mathrm{d}} \cdot \mathrm{XA}
$$

which results is a critical flow rate of

$$
\mathrm{Q}=9.062 \times 10^{3} \mathrm{gpm}
$$

\section{DISCUSSION OF RESULTS}

The theoretical collapse velocity for flat plates with simply supported edges was calculated first. Then, the ratio of the critical velocity of hinged curved plates to that of hinged flat plates was calculated. The critical velocity for the hinged curved plate assembly was calculated by multiplying the predicted collapse velocity for hinged flat plate assemblies by this critical velocity ratio. Due to the higher stiffness of the curved plate assembly, the critical velocity is approximately 15 times higher than that for a long flat plate assembly with identical dimensions.

The predicted plate collapse velocity, $\mathrm{U}_{\mathrm{d}}$, for the GTL booster fuel assembly is $228 \mathrm{~m} / \mathrm{s}(749 \mathrm{ft} / \mathrm{s})$. This would occur at a total coolant flow rate around $9100 \mathrm{gpm}$. Preliminary calculations performed using RELAP5-3D using a fuel plate surface roughness of 1.31 microns, predict an average coolant flow velocity of approximately $10.5 \mathrm{~m} / \mathrm{s}(34.4 \mathrm{ft} / \mathrm{s})$ with the snubber tube included and $13.4 \mathrm{~m} / \mathrm{s}(44.0 \mathrm{ft} / \mathrm{s})$ without the snubber tube. The total coolant design flow rate without the snubber tube is $533 \mathrm{gpm}$ [10]. The snubber tube is part of the original ATR design intended to hydraulically slow the control rod as it reaches the bottom of its travel path.

Miller states "in some fuel-plate assemblies collapse has occurred at velocities on the order of one-half of that predicted by the formulas here" [3]. In the absence of a considerable margin between the theoretically predicted plate collapse velocity and the design velocity, a test program would be warranted. However, since the coolant design flow velocity is only $6 \%$ of the predicted critical flow velocity based upon Miller's theory, the phenomena of plate collapse due to static instability is unlikely. However, this does not rule out the possibility of plate collapse caused by other mechanisms, such as thermoelastic instability, creep, radiation-induced fuel meat distortion, etc., which may need to be investigated.

\section{ACKNOWLEDGMENTS}

This manuscript has been authored by Battelle Energy Alliance, LLC under Contract No. DE-AC07-05ID14517 with the U.S. Department of Energy. References herein to any specific commercial product, process, or service by trade name, trademark, manufacturer, or otherwise, does not necessarily constitute or imply its endorsement, recommendation, or favoring by the U.S. Government, any agency thereof, or any company affiliated with Idaho National Laboratory.

\section{REFERENCES}

1. "Justification of Mission Need for the Gas Test Loop," Idaho National Laboratory, INEEL/EXT-04-02018, June 2004.

2. Longhurst, G.R., and Khericha, S.T., "Gas Test Loop Technical and Functional Requirements," Draft, Rev. A, Idaho National Laboratory, INEEL/EXT-04-02273, July 2005.

3. Miller, D.R., "Critical Flow Velocities for Collapse of Reactor Parallel-Plate Fuel Assemblies," Journal of Engineering for Power, April 1960, p. 83-95.

4. Stromquist, W.K., and Sisman, O., "High Flux Reactor Fuel Assemblies - Vibration and Water Flow," Report No. ORNL-50, June 15, 1948

5. Doan, R.L., "The Engineering Test Reactor - A Status Report," Nucleonics, Vol. 16, No. 1, 1958, p. 102-105.

6. Ho, M., Hong, G., and Mack, A.N.F., "Experimental Investigation of Flow-Induced Vibration in a Parallel Plate Reactor Fuel Assembly," $15^{\text {th }}$ Australasian Fluid Mechanics Conference, Sydney, Australia, December 13-17, 2004.

7. Païdoussis, M.P., Fluid-Structure Interactions: Slender Structures and Axial Flow, Vol. 2, Elsevier Academic Press, New York, 2004, p. 1181-1186.

8. 2004 ASME Boiler \& Pressure Vessel Code, Section II, "Materials," Part D, "Properties (Customary)," Subpart 2, "Physical Property Tables," Table TM-2, "Moduli of Elasticity $E$ of Aluminum and Aluminum Alloys for Given Temperatures," American Society of Mechanical Engineers, 2004 Edition, 2005 Addenda.

9. Mark's Standard Handbook for Mechanical Engineers, $8^{\text {th }}$ Edition, McGraw Hill, New York, 1978, Table 3, p $5-5$. 
10. Guillen, D.P., and Yoder, T.S., "Specification of

Surface Roughness for Hydraulic Flow Test Plates,"

Proceedings of the $5^{\text {th }}$ International Surface

Engineering Congress, Seattle, WA, May 15-17, 2006. 